\title{
The Impact of Lecture Attendance on Exams for Novice Programming Students
}

\author{
Ashok Kumar Veerasamy \\ Department of Information Technology, University of Turku, Turku, Finland \\ Email: askuve@utu.fi \\ Daryl D'Souza \\ Department of Computer Science and Information Technology, RMIT University, Melbourne, Australia \\ Email: daryl.dsouza@rmit.edu.au
}

\section{Rolf Lindén}

Department of Information Technology, University of Turku, Turku, Finland

Email: rolind@utu.fi

Erkki Kaila

Department of Information Technology, University of Turku, Turku, Finland

Email: ertaka@utu.fi

Mikko-Jussi Laakso

Department of Information Technology, University of Turku, Turku, Finland

Email:milaak@utu.fi

Tapio Salakoski

Department of Information Technology, University of Turku, Turku, Finland

Email: tapio.salakoski@utu.fi

\begin{abstract}
In this paper, the correlation between lecture attendance and assessment tasks on final exam performance of introductory programming students has been analyzed to identify if lecture attendance, and completion of in-class and take home formative assessment tasks affects student performance in the final examination. In this study, only lecture attendance, homework exercises and class demonstration scores, and final exam marks have been considered. This study used Spearman's Rank correlation coefficient and multiple regression techniques via SPSS software to analyze the student data of the academic years 2012, 2013 and 2014 of an introductory programming course to test the hypotheses. It is found that, there is a significant correlation between homework exercises and final exam scores. However, formal lecture attendance and final exam performance were negatively correlated. Moreover, multiple regression results of assessment tasks such as homework exercises, class activities and lecture attendance on final exam scores, did not provide any significant value to support the statement "Marks achieved in homework, class demonstrations, and lecture attendance, have a significant positive impact on final examination results".
\end{abstract}

Index Terms-Educational technologies, Lecture attendance, Shapiro-Wilk test, Multiple regression.

\section{INTRODUCTION}

In higher education it is commonly assumed that students who attend lectures will perform better in assessment tasks and the subsequent final exam $[1,2,3]$. Indeed, lecture attendance is one of the important factors that influence student learning and academic performance [4]. For example, attending lectures helps students to revise the content that already exists in electronic form and provides the opportunity to engage in learning. Notably, lecture attendance is one of the key determinants of academic performance in many courses $[1,5]$. However, this assumption needs to be tested due to the radical impact of educational technologies on student learning and performance. Do educational technologies influence student lecture attendance and performance in assessment tasks? The emerging use of educational technologies within higher education has changed the traditional lecture sessions into a more interactive one [6]. Moreover, user friendly visualization tools stimulate educators to update their instructional design in alignment with the objective of technology enhanced learning. Notably, the e-learning enables students to learn by themselves [7]. It has also been observed that numerous e-learning platforms available via the Internet facilitate students to access lecture slides, step by step tutorials, and coding exercises to practice at anytime and anywhere 
$[8,9]$. In addition, lecture recordings are archived by educators at these e-learning platforms for students who are otherwise unable to attend lectures, to download and learn. Apart from above, the influence of the digital era imposes the need of variety of teaching strategies including educational technologies to increase student lecture attendance. Moreover, the effectiveness of educational technologies in learning may have impacted on student lecture attendance. So, it is important to analyze the impact of lecture attendance where educational technologies have encouraged students to be self-sufficient learners.

Programming courses are the core of computer science curricula and usually one of the first courses studied by novices $[10,11]$. These fundamental courses give students the opportunity to understand the computational approaches to problem solving. However, it is identified that learning to programming is difficult task for many students. Also, the difficulty of learning to program pushes students from other programs to avoid taking programming courses and to select alternative courses [12, 13]. Apart from this, programming requires students to have a good understanding of programming concepts and meta-cognitive skills in order to be proficient in computer programming [14]. Moreover, students who perform well in programming use their metacognitive skills and achieve higher grades than those who do not [15, 16, 17]. These reasons emphasize to educators to make learning more interactive to increase student lecture attendance. For example, enquiry based learning or problem based teaching will be more effective than simply presenting the information with examples and pictures in lecture. So, teachers are always looking for effective teaching methods to enhance student motivation, problem solving and metacognitive skills in learning programming. Notably, there has been much research done on how to teach programming courses in interesting and effective ways to novices [14, 18, 19, 20, 21, 22]. However, those proponents accepted that "formal lectures are not a useful way of teaching programming" [10, 23]. Furthermore, students skip classes sometimes, despite teachers employing mind provoking teaching techniques to entice students into regularly attending classes. So, these problems need to be resolved due to the importance of programming courses and should be addressed with special care [24, 25]. Moreover, educational theory and innovative educational technologies suggest that lecture based classes may not be the best way to impart knowledge of students [26, 27, 28]. So, it is important to reexamine the impact and requirement of formal regular lecture sessions in connection with programming courses.

In addition, we observed that students who did not attend lecture sessions regularly were also able to complete formative assessment tasks such as homework and in-class assessment-based demonstration activities, and still achieve good scores in the final programming exam. Taking this initial observation as our starting point, the aim of this research is to identify the impact of lecture attendance on assessment tasks and the subsequent final examination through valid statistical methods.
Numerous science education studies also have been conducted on focusing on the question "which teaching strategies and assessment tasks can foster student learning and academic performance" [29]. Furthermore, improving teaching quality, student attendance, and academic success is always a main concern for educators. Despite the mixed impact of lecture attendance and assessment tasks on student achievement [30, 31], the academic communities often come up with different types of teaching activities and assessment tasks to improve student attendance, learning and academic performance [32, 33, 34, 35]. However, although many studies analyzed the impact of lecture attendance on formative assessment tasks in students' academic achievement, the impact of non-lecture attendance and formative assessment tasks such as homework exercises and class demonstration on final exam results in novice computer programming courses is not yet fully analyzed. Moreover, none have yet examined the impact of formal lecture attendance on results of web based home work exercises, which provide automatic feedback and results, and final e-programming exams.

Hence, given the importance of introductory programming courses $[5,36]$, it is evident to find the impact of lecture attendance on formative assessment tasks and final examination performance. Towards this aim, this paper addresses the following research questions.

1. Does homework and class demonstration together help students to do well in the final programming exam?

2. Does lecture attendance influence student performance in performing assessment tasks and performing better in the final programming exam?

In order to find answers to these research questions we collected and analyzed introductory programming course students' lecture attendances, web based home work and demonstration exercises, and final exam data. It is expected that students who attend lectures, and complete assessment tasks, such as homework and class demonstrations, successfully during the course of study, will perform significantly better in the final exam than those who do not do.

This paper is further divided into four sections. Section II presents a literature review of studies involving the impacts of lecture attendance and assessment tasks, such as homework exercises and class demonstration activities, on student achievement in final programming examination. Section III presents the research methodology with details of assessment tasks that were chosen for data analysis. Section IV presents the research outcomes, and finally Sections V and VI discuss these results and present the conclusions. 


\section{LITERATURE REVIEW}

In this section we survey the literature in the context of a typical semester long course in programming with a focus on assessment, lecture attendance and the impact of lecture attendance. In addition, we survey the current literature concerning the impact of educational technologies on learning, lecture attendance and student achievement in final exam.

\section{A. Assessment Tasks}

In education the term assessment task refers to a collection of methods used by educators to evaluate student performance. Assessment tasks impact student learning and academic performance. Moreover, it is a scholastic tool to regularly evaluate student learning outcomes, thus allowing teachers to monitor and provide appropriate feedback to students on their learning [2, 3]. Assessment tasks represent one of the core contributors in teaching and learning and play a significant role in terms of student grading. Moreover, assessments are mirrors of what students learn during educational processes [40]. Educators use assessment tasks as monitoring instruments to discover student learning difficulties and suggest remedial methods to improve student learning skills [3]. For example, a formative assessment task takes place during the course of study. Moreover, these tasks are mainly used to monitor student learning throughout the study period. Educators use formative assessment tasks to recognize where students are struggling in order to help them and to address those problems in their teaching. For example, formative assessment tasks such as homework and in-class activities are provided during the course of study to measure student progress. Similarly, summative assessment is used by educators to measure the student learning at the end of a course of study. For example, final exams are a significant summative assessment given to students at the end of a course to measure student learning outcomes [37, 38]. Furthermore, the results of final exams are partly used to determine students' final grades.

There has been much research done on the importance of formative and summative assessment tasks in teaching and learning, notably connected with academic performance [31, 41, 42]. Formative assessment tasks influence student academic achievement. Students who participate in formative assessments perform significantly better in the final exam than those who do not [43]. For example, homework is one of the ongoing formative assessment tasks used by educators to evaluate student learning performance. Eren et al. conducted a study on impact of homework and test results, and concluded that homework is an important determinant of student exam scores [42]. Furthermore, providing smaller but more frequent formative type assessment tasks improves students' overall performances in lab work, although this kind of formative assessment task has no significant impact on final exam scores and failure rates [2, 31]. In addition, Gaal et al. identified that students' performance in assessment tasks make no significant contribution to their subsequent examination marks [31].

The literature relevant to the impact of formative and summative assessment tasks in connection with novice programming courses states that assessments are one of the possible predictor that influence the novice programming student achievement [44]. Assignment is one of the common formative types of assessment tasks frequently used to grade student's performance and provide timely feedback in engineering courses [2]. In addition, lab exercises and lab exams are common assessment tasks used in programming courses to measure student coding skills for grading [45]. Notably, many instructors agreed that summative assessment can provide a valid measure of a student's ability to program [46]. Feedback on formative assessments helps students to improve their learning [47]. Corbett et al. reported that feedback on formative assessments can be used by educators in programming courses to improve the programming efficient of novices [48]. However, Koulouri et al.'s study on the impact of formative assessment feedback in teaching introductory programming reported different results. Their results supported Irons' research findings that provision of formative assessment feedback in introductory programming did not yield any benefits to novices in terms of improving academic performance [36, 41]. However, on the other hand, it is often believed that students who are high lecture attendees perform significantly better in the final exam and other assessment tasks than those who attend lectures less frequently [30].

\section{B. Impact of Lecture Attendance}

Attendance in lectures is identified as one of the determinants of student performance [55]. Attending classes yields a positive impact on exam performance [1, $56,57]$. There have been studies done on impact of student non-attendance at lectures on formative assessment tasks and final grades, and relationship between lecture attendance and final exam in various courses [4, 30, 31]. However, the results of those studies varied from one academic environment to another due to differences in student cohorts, cultural settings, and education systems [39].

According to Marburger, a compulsory attendance policy prevents students from missing classes and also improves exam performance [35]. Also, students who miss classes early in the semester perform badly in the exams $[58,59]$. However, the effect of lecture attendance on academic performance may vary due to the student demographics, perceived difficulty of the class, and education setup [8, 60, 61]. Latif et al. found that students who attend classes and complete online assignments on a regular basis achieve higher grades [4]. Pudaruth et al. conducted a study to identify the impact of lecture attendance on the academic performance of university computer science students in various courses including computer programming, and concluded that students who attended formal lecture sessions performed well in the computer programming course however, the strength of 
correlation varied greatly for other computing courses [8] However, Horten et al. reported that lecture attendance has no significant impact on student performance in assessment tasks [30]. In addition, Bellaby et al. stated that conducting lecture sessions are not a suitable way to teach programming [23].

\section{Impact of Educational Technologies}

Educational technologies have changed the traditional classrooms into technology-enhanced classrooms, and often present intriguing tools to enhance learning. The teaching and learning processes are enhanced by educational technologies [62]. In addition, technology enabled assessment tasks provide paperless test distribution, immediate feedback on student-submitted course work, and foster student motivation and interest in learning [49, 50]. For example, online quizzes and multiple-choice questions are used in programing courses to test students' understanding of language syntax or program behavior [51]. In addition, practical work submitted via automated assessment tools such as Petcha, TRAKLA, and ViLLE, provides immediate feedback with scores [32, 50, 52, 53]. Also, coding assessments that use resubmission mechanisms enabled automated feedback system fosters student coding skills [54]. An example, a ViLLE is an e-learning tool that is primarily based on exercises and used by our IT students to practice programming exercises. Notably, lecture recordings are also made available in the Moodle e-learning system for students to download lecture notes, tutorials and additional exercises. Students can learn anytime and submit their completed assessment work online without attending classes. Furthermore, students seem to agree that the availability of class lecture recordings encourage them to skip or miss the classes [63]. Similarly, students prefer to complete online assignments rather than paper based assignments. Apart from these, assignment completions - on paper or online help students to perform better in the subsequent examination. However, it is found that there is no positive relationship between assessment marks and exam performance [33].

The studies cited above endorse that educational technology enhanced courses and e-assessment tasks may influence student lecture attendance and achievement in final exams. However, to the best of our knowledge, although there has been much research on impact of assessment tasks in various courses [4, 5, 35, 39, 59, 64], relatively little research has been done on the impact of homework exercises and lecture attendance on novice computer programming final exam performance. Our study focused to find the relationship between lecture attendance and formative assessment tasks such as homework and demonstrations, and between lecture attendance and final exam results in an introductory programming course.

\section{RESEARCH METHOD}

The primary purpose of this research was to examine the impact of results of lecture attendance and assessment tasks on final programming exam results. Hence, in this study we attempt to measure the impact of lecture attendance on the student academic performance in introductory programming, in which lecture attendance was not compulsory. Introductory programming is offered once a year (spring semester) to students from different disciplines who have no prior knowledge in programming. The course comprises 26 hours of lectures, 20 hours of demonstration sessions, and 10 hours for practice exam and discussion of project work/assignment work. Three spring semesters (2012, 2013 and 2014) of student academic data were examined for this study. In total, over the three years, there were 167 students enrolled in the course. However, only 116 students attended the electronic final examination including the demonstration sessions. The study was therefore limited to the academic data of 116 students who attended the formal lectures, and demonstration sessions and the efinal exam in order to identify the impact of lecture attendance and assessment tasks on subsequent final exam performance.

To do so, lecture attendance, ViLLE e-learning tool enabled homework exercises, in class demonstration session scores, and e-final exam marks of respective course students have been analyzed. Marks for tutorials and lab exercises have not been considered as these are not taken into account for final grade calculation of this course. Moreover, tutorials and lab sessions were done in groups of two or three students. This study used the SPSS software to store and analyzes the data. We also used Spearman's Rank correlation coefficient and multiple regression techniques to identify the linear association or correlation between non independent variables such as lecture attendance and selected assessment tasks.

\section{A. Overview of Assessment Tasks}

The assessment for this course comprises ViLLE based weekly exercises, homework, project work, coding exercises for class demonstrations (Moodle) and an online-final examination (e-exam).

\section{B. Moodle and ViLLE}

Moodle is an open source software course management system $[65,66]$ used in the introductory programming course to deliver lecture materials, course related announcements, and coding exercise files for demonstration session.

ViLLE is software used in the introductory programming course to support technology enhanced programming classes [67]. ViLLE is mainly used to provide homework, lab exercises, and class work and to conduct e-exams for programming courses. All programming exercises are posted via ViLLE including homework and classwork to practice and grade submitted answers automatically. 


\section{Homework Exercises $(H E)$}

Each set of homework exercises (HE) is provided weekly for a total of 8 weeks. These sets of exercises are prepared based on chapter (lecture notes) and each set has an average of 5-10 questions, which contain objective type, code tracing, visualization and coding exercises. These exercises are offered to students via ViLLE to submit their answers electronically. Student submitted work is automatically graded by ViLLE but coding and a few visualization exercises are graded and the scores entered by the lecturer manually, into the ViLLE system, to calculate the bonus points for the final grade. The possible total HE component score is 600. The HE component is a hurdle and student should secure at least $50 \%$ marks in this component to pass the course.

\section{Demonstration $(D E)$}

Demonstration (DE) is an assessment task conducted once a week after a lecture session, over 10 weeks. All students are expected to complete 5-7 coding exercises that are posted via Moodle, before attending a DE session. In a DE session, all students' solutions to the questions are discussed by the lecturer, and a few students are selected randomly via ViLLE, to demonstrate their answers in the class. No marks are awarded for class demonstrations. However, students who complete the DE exercises are instructed to enter their responses into ViLLE enabled in lecturer's computer to record the number of DE-exercises completed by them. The marks for DE-exercises are calculated at ViLLE software based on their registered responses in the lecturer's computer. The possible total score is 750. The DE is a hurdle and student should secure at least $50 \%$ in the DE component to pass the course.

\section{E. Project / Assignment Work $(P W)$ and Practice Exam $(P X)$}

Student queries related to project and assignment work are discussed during the discussion sessions. The marks for PW are calculated via ViLLE. The total possible PW score is 7. However, marks for PW have not been considered for data analysis as these were done in groups of two or three students.

The practice exam is conducted just before the end of the last week of the course of study, to prepare students for the final exam. This exam is conducted electronically by using ViLLE. The maximum possible score for PX is 60. However, PX is not compulsory and not taken into account when calculating the course grade.

\section{F. Lecture Attendance (LA)}

Students who enrolled in the Introduction to Programming course receive a smart device called a ViLLE tag to record lecture attendance. Every tag has its own unique ID and easy to differentiate every tag holder. The ViLLE enabled system is used to store and calculate student data and attendances, for those who attend the classes. Students must scan their tag while entering the lecturing theatre. Although, attending lecture is not compulsory, students who attend $80-95 \%$ s of all lecture sessions receive 3 bonus points and students who attend above $95 \%$ of lecture sessions receive 5 bonus points. The awarded bonus points will be added to the student's final grade points to calculate the course final grade. The maximum possible score for lecture attendance (LA) is 120 (LA's actual values were converted for data transformation).

\section{G. Final Examination (FE)}

The final examination (FE) is conducted at the end of the course of study. This FE is conducted electronically by using ViLLE. The duration of the e-exam is 180 minutes. The FE is a hurdle and students should secure at least $50 \%$ to pass the course. Moreover, students are only eligible to sit the FE if they secure at least $40 \%$ in the course assignments, 50\% marks in the $\mathrm{HE}$, and $50 \%$ marks in the DE. The exam is divided into two parts, namely, multiple choice questions \& short answers, and coding segments. The maximum possible total score for $\mathrm{FE}$ is 100 .

\section{H. Hypothesis Development}

Based on the foregoing literature review on impact of lecture attendance on subsequent formative and summative assessment tasks, our observation on programming students' final scores of both types of assessment tasks, the following hypotheses were developed to answer our research questions.

H1: Students who complete homework exercises prior to participating in class discussions + demonstration perform significantly better than students who do not complete homework exercises prior to attending the class discussion + demonstration.

$\mathrm{H} 2$ : Students who achieve high scores in homework exercises perform significantly better in final examination than students who achieve low scores.

H3: Lecture attendance has a positive significant impact on homework exercises results.

H4: Lecture attendance has a positive significant impact on final examination results.

H5: Students who achieve high scores in homework exercises and class demonstrations perform significantly better in the final examination, than those who do not.

H6: Marks achieved in homework, class demonstrations, and lecture attendance, have a significant positive impact on final examination results.

Hypotheses $\mathrm{H} 1$ and $\mathrm{H} 2$ were defined to answer the research question 1 and $\mathrm{H} 3$ and $\mathrm{H} 4$ were developed to identify the answer for our research question 2. In addition, hypotheses H5 and H6 were developed to identify the collective impact of lecture attendance, formative and summative assessment tasks on subsequent final examination to identify the key determinant of academic performance. 


\section{DATA ANALYSIS AND RESULTS}

This study investigated the Introduction to programming (Python) course results for LA, HE, DE and FE, using data from 2012, 2013, and 2014 to measure the results against defined hypotheses. The academic data were collected via ViLLE and SPSS software was used for statistical analysis. This study used 116 students' academic data, those attended the final exam. We conducted a normality test (Shapiro-Wilk test) to identify how the data are distributed in order to apply appropriate statistical techniques to avoid statistical errors [68]. The collected academic data was examined through the Shapiro-Wilk test with the null hypothesis "the data are normally distributed". However, it was identified that the p-value of the test was less than the alpha level. Hence, the null hypothesis was rejected. This means the data were not normally distributed. Hence, this study used the Spearman's Rank correlation coefficient technique to measure the statistical dependence between two variables. In addition, we used multiple regression technique to find if attending classes, and completing e-assessment tasks together (homework and class discussions + demonstration) impact student's achievement in final exam scores. Consequently, the data analysis is divided into two phases to perform the statistical hypothesis testing on collected academic data. These are presented below.

\section{A. Phase 1-Spearman's Rank Correlation Technique (SpRT): Hypothesis testing (H1-H4)}

Spearman's rank correlation coefficient technique (SpRT) is a statistical test to measure the association between two variables [69]. The purpose of this analysis is to perform the statistical hypothesis testing with SpRT to measure the association between students' scores of take homework exercises (HE), demonstration exercises (DE), and, lecture attendance (LA), and final exam (FE). We used SpRT to test our hypotheses H1-H4. I.e. to measure the strength and the direction of monotonic relationship between the scores of

\section{H1: HE and DE, \\ $\mathrm{H} 2$ : $\mathrm{HE}$ and $\mathrm{FE}$, \\ $\mathrm{H} 3$ : LA and HE, and \\ $\mathrm{H} 4$ : LA and FE}

for the years 2012, 2013 and 2014 individually.

Table 1 shows the summary of Spearman's Rank correlation results of our hypothesis testing between the assessment task variables, for the years 2012, 2013 and 2014.

\section{B. Phase 2 - Multiple Regression Technique (MRT): Hypotheis testing (H5 and H6)}

Multiple regression allows us to examine if there any linear relationship between one or more independent variables on one dependent variables [70]. The purpose of this analysis is to identify the impact of $\mathrm{HE}, \mathrm{DE}, \mathrm{LA}$ variables on the dependent variable FE. We used MRT to test our defined hypotheses H5 and H6. That is, the impact of

H5: HE and DE on FE scores, and

H6: HE, DE, and LA on FE scores,

for the years 2012, 2013 and 2014 separately.

Table 1. Correlation coefficient results: 2012 versus 2013 versus 2014

\begin{tabular}{|c|c|c|c|}
\hline Variables & \multicolumn{3}{|c|}{ Spearman's Rank correlation } \\
\cline { 2 - 4 } $\begin{array}{c}\text { No. of students : } \\
\text { 29 (Year 2012) } \\
42 \text { (Year 2013) } \\
45 \text { (Year 2014) }\end{array}$ & $\begin{array}{c}\text { Year } \\
2012\end{array}$ & $\begin{array}{c}\text { Year } \\
2013\end{array}$ & $\begin{array}{c}\text { Year } \\
2014\end{array}$ \\
\hline $\begin{array}{c}\text { H1: Results of HE } \\
\text { on DE scores }\end{array}$ & 0.520 & 0.480 & 0.693 \\
\hline $\begin{array}{c}\text { H2: Results of HE } \\
\text { on FE scores }\end{array}$ & 0.675 & 0.459 & 0.310 \\
\hline $\begin{array}{c}\text { H3: Results of LA } \\
\text { on HE scores }\end{array}$ & 0.127 & 0.161 & 0.616 \\
\hline $\begin{array}{c}\text { H4: Results of LA } \\
\text { on FE scores }\end{array}$ & -0.012 & -0.036 & -0.015 \\
\hline
\end{tabular}

Tables 2, 3 and 4 present the summary of MRT's results of our hypothesis testing which indicates the impact of HE, DE, and LA on FE results, for the years 2012, 2013 and 2014.

Table 2. Multiple regression results (stepwise method): 2012 (number of students $=29$ )

\begin{tabular}{|c|c|c|c|}
\hline Variables & $\mathbf{R}$ & $\mathbf{R}^{2}$ & Remarks \\
\hline $\begin{array}{l}\text { H5: Results of } \\
\text { HE, and DE on } \\
\text { FE scores }\end{array}$ & 0.527 & 0.278 & $\begin{array}{l}\text { The coefficient } \\
\text { for HE }(0.223) \text { is } \\
\text { significantly different } \\
\text { from } 0 \text { because its p- } \\
\text { value is } 0.016 \text {, which is } \\
\text { smaller than } 0.050 \text {, but } \\
\text { DE's p-value is } 1.000\end{array}$ \\
\hline $\begin{array}{l}\text { H6: Results of } \\
\text { HE, DE, and LA } \\
\text { on final exam } \\
\text { scores }\end{array}$ & 0.527 & 0.278 & $\begin{array}{l}\text { The coefficient for HE } \\
(0.222) \text { is significantly } \\
\text { different from } 0 \text { because } \\
\text { its p-value is } 0.020 \text {, } \\
\text { which is smaller than } \\
0.050 \text {, but DE p-value is } \\
0.988 \text {, and LA's p-value } \\
\text { is } 0.977 \text {. }\end{array}$ \\
\hline
\end{tabular}

Table 3. Multiple regression results (stepwise method): 2013 (number of students $=42$ )

\begin{tabular}{|c|c|c|c|}
\hline Variables & $\mathbf{R}$ & $\mathbf{R}^{2}$ & Remarks \\
\hline $\begin{array}{l}\text { H5: Results of } \\
\text { HE, and DE on } \\
\text { FE scores }\end{array}$ & 0.343 & 0.118 & $\begin{array}{l}\text { The coefficient for HE } \\
(0.056) \text { is significantly } \\
\text { different from } 0 \text { because } \\
\text { its p-value is } 0.046 \text {, } \\
\text { which is smaller than } \\
0.050 \text {, but DE's p- } \\
\text { value is } 0.672\end{array}$ \\
\hline $\begin{array}{l}\text { H6: Results of } \\
\text { HE, DE, and LA } \\
\text { on final exam } \\
\text { scores }\end{array}$ & 0.345 & 0.119 & $\begin{array}{l}\text { None of the selected } \\
\text { independent variables' } \\
\text { coefficient values are } \\
\text { significantly different } \\
\text { from } 0 .\end{array}$ \\
\hline
\end{tabular}


Table 4. Multiple regression results (stepwise method): 2014 (number of students $=45)$

\begin{tabular}{|c|l|l|l|}
\hline Variables & \multicolumn{1}{|c|}{$\mathbf{R}$} & $\mathbf{R}^{2}$ & \multicolumn{1}{|c|}{ Remarks } \\
\hline $\begin{array}{c}\text { H5: Results of } \\
\text { HE, and DE on } \\
\text { FE scores }\end{array}$ & 0.474 & 0.225 & $\begin{array}{l}\text { The coefficient for DE } \\
(0.063) \text { is significantly } \\
\text { different from 0 because } \\
\text { its p-value is 0.001, which } \\
\text { is smaller than 0.05, but } \\
\text { HE's p-value is 0.070 }\end{array}$ \\
\hline $\begin{aligned} \text { H6: Results of } \\
\text { HE, DE, and LA } \\
\text { on final exam } \\
\text { scores }\end{aligned}$ & 0.532 & 0.283 & $\begin{array}{l}\text { The coefficient for DE } \\
(0.072) \text { is significantly } \\
\text { different from 0 because } \\
\text { its p-value is 0.000, which } \\
\text { is smaller than } 0.050, \text { but } \\
\text { HE p-value is } 0.297, \text { and } \\
\text { LA's p-value is } 0.075 .\end{array}$ \\
\hline
\end{tabular}

The multiple regression results of Tables 2,3 , and 4 reflect that the effect of $\mathrm{HE}$ on the $\mathrm{FE}$ is significant for all the years $(2012-2014)$. However, the effect of LA on the FE is not significant for the years $2012-2014$. On the other hand, the results of DE on the FE are significantly effective for the year 2014 but not so significant for the years 2012 and 2013.

\section{DISCUSSION}

Our research results show that there is a significant difference in relationship between the selected assessment tasks results and the final exam performance from one academic year to next. The Spearman's Rank correlation coefficient results $(\mathrm{SpR})$ in Table 1 show that for years 2012 - 2014 results of homework exercises have positive significant correlation relationship (average $\mathrm{SpR}=0.564$ ) with class discussion + demonstration results Notably, these results support our Hypothesis 1 (H1). From these results we conclude that ViLLE assessment task "homework exercises with solutions and automated feedback" helped the students to learn the topics deeply and performed significantly better in demonstration exercises than students who did not complete homework exercises.

The most common purpose of homework is to provide the student with an opportunity for independent learning. In addition, most educators believe that homework affects student academic achievement. However, the influence of homework on student achievement may vary from student to student, depending on how much each student is assigned or completed [71]. The correlation results for the years 2012 and 2013 on hypothesis 2 (H2) support the Eren et al. conclusion that homework can be a one of the determinants to identify student achievement [42]. We found that there was a positive significant relationship between the homework scores and final exam results for 2012 and 2013, though 2013's SpR was mildly significant. However, our study yielded different results from student homework and exam scores for 2014 and did not support $\mathrm{H} 2$ strongly, though the correlation result was positive. The correlation results for 2014 revealed that student performance on homework exercises has less significant influence $(\mathrm{SpR}=0.310)$ on their final exam results. In addition, the results for 2014 supporting the Harris et al.'s finding that the impact of homework on student learning and achievement is complex [71].

There has been much research done on the link between lecture attendance and student performance. It is identified that students who attend lecture sessions regularly perform better in their assessment tasks. Moreover, a number of studies suggest that lecture attendance can be considered as one of the determinants to identify student performance [4, 55, 64, 72]. Year 2014's SpR supported those previous studies and Hypothesis 3 (H3) partially that, attending formal lecture sessions has a direct impact on student assessment task performance, notably homework exercises $(\mathrm{SpR}=0.616)$. However, for years 2012 and 2013 the correlation results did not support H3 though SpR results of those were positive but significant, which supported Horton et al. conclusion that lecture attendance and assessment outcomes are weakly correlated [30].

In addition, the correlation results for lecture attendance and the final exam revealed that attending formal lecture sessions has no impact on student final exam performance. The SpR of lecture attendance and final exam was mildly negative neither or nor support our hypothesis $4(\mathrm{H} 4)$. Moreover, from these results the following points emerged. First, Python was introduced as the language for the introductory programming course which is simple and expressive language for students to learn independently. Second, exercises and tasks provided for students to assess their performance might be not sufficiently challenging to attend classes, to know more. Third, the availability of alternative sources of materials might have made students utilize those as substitute for lectures and also able to get high scores in the final exam [30]. However, these points should be analyzed further. Finally, Moodle and ViLLE were used in this course to provide learning materials and exercises. Notably, ViLLE was used to evaluate student work submitted in the system automatically, and to provide instant feedback. So, these educational technology enhanced learning features would have helped students to learn programming notably those who skipped lecture sessions. However, this assumption needs to be analyzed further.

The multiple regression results in Tables 2, 3, and 4 for years 2012-2014 present that the effect of assessment tasks and lecture attendance together on final exam performance. Tables 2, 3 and 4 support Hypothesis 5 (H5) partially, that assessment tasks have impact on final examinations though results of class discussions + demonstration activities did not yield a significant $\mathrm{p}$ value. Similarly, the multiple regression results of assessment tasks and lecture attendance on final exam scores were not significant to support Hypothesis 6 (H6). Notably, the HE, DE and LA results on FE score for years 2012 and 2013 reveal that demonstration exercises and activities results suggest that DE assessment tasks did not provide any significant impact on subsequent final examination performance. However, the results of the year 2014 were completely opposite. So, DE may not be 
considered as one of the key determinants of academic performance in a programming course. However, this conclusion is derived based on the regression results for years 2012 - 2014 only. So, it needs to be reanalyzed further to support our conclusion. Apart from these, our study results were partially similar to the findings of Gaal et al. that "formative assessments make no significant impact to their subsequent final exam scores" [31].

\section{CONCLUSION}

Our study identified that lecture attendance and student final exam performance was negatively correlated. However, ViLLE learning environment, materials and exercises helped novices to learn and perform well in the final exam and other assessment tasks, though the results varied significantly from year to year. These results provide immediate information for novice programming course instructors to analyze further to find the factors that prevent novices from attending programming formal lecture sessions. In addition, impact of demonstration assessment tasks should also be reanalyzed in relation to student characteristics, which varies from year to year. Finally, data and the results of this will be used for our further research to identify the learning style or learning preferences of novice programming students.

This research has a few limitations. First, the results of this study are derived from a specific course of the university. So, it is not adequate enough to generalize our findings. Second, this study did not focus on student prior knowledge in programming, and non-cognitive variables such as motivation, self-efficacy, and gender. Finally, the marks achieved by students in formative and summative assessment tasks might not truly reflect the student's knowledge of this course. For example, a student might be repeating the course.

Further, this research could be conducted to identify the impact of assessment tasks on final examination and or final grades in alignment with psychological factors such as, self-efficacy and motivation, self-regulation, learning style, study habits. In addition, this research could be extended to examine "Whether gender plays a significant role in achieving better scores in assessment tasks". Finally, this study will also be implemented to different courses, institutions, countries and with different student populations to explore the impact of formative and summative assessments on lecture attendance. Apart from the above, further research might measure the impact of technology enabled assessment tasks on student learning.

\section{ACKNOWLEDGEMENT}

The authors wish to thank all members of ViLLE team research project group, Department of Information Technology, University of Turku for their comments and support that greatly improved the manuscript. This research was supported fully by a grant from ViLLE team project, University of Turku, Turku, Finland.

\section{REFERENCES}

[1] L. Stanca, "The Effects of Attendance on Academic Performance: Panel Data Evidence for Introductory Microeconomics," The Journal of Economic Education, vol. 37, no. 3, pp. 251-266, 2006.

[2] I. Gratchev and A. Balasubramaniam, "Developing assessment tasks to improve the performance of engineering students," in 23rd Annual Conference of the Australasian Association for Engineering Education 2012, Melbourne, 2012.

[3] E. Trumbull and A. Lash, Understanding Formative Assessment: Insights from Learning Theory and Measurement Theory, San Francisco: WestEd, 2013.

[4] E. Latif and S. Miles, "Class Attendance and Academic Performance: A Panel Data Analysis," Economic Papers, vol. 32, no. 4, pp. 470-476, 2013.

[5] M. Narula and P. Nagar, "Relationship Between Students' Performance and Class Attendance in a Programming Language Subject in a Computer Course," International Journal of Computer Science and Mobile Computing, vol. 2, no. 8, pp. 206-210, 2013.

[6] J. Al-Ammary, "Educational Technology: A Way To Enhance Student Achievement At the University of Bahrain," in 3rd International Conference on New Horizons in Education - INTE 2012, Prague, Czech Republic, 2012.

[7] M. Dominic, S. Francis and A. Pilomenraj, "E-Learning in Web 3.0," International Journal of Modern Education and Computer Science, vol. 2, pp. 8-14, 2014.

[8] S. Pudaruth, L. Nagowah, R. Sungkur, R. Moloo and A. Chiniah, "The Effect of Class Attendance on the Performance of Computer Science Students," in 2nd International Conference on Machine Learning and Computer Science(IMLCS'2013), Kuala Lumpur (Malaysia), 2013.

[9] R. Anand, S. Saxena and S. Saxena, "E-Learning and Its Impact on Rural Areas," International Journal of Modern Education and Computer Science, vol. 5, pp. 46-52, 2012.

[10] Á. Matthíasdóttir, "How to teach programming languages to novice students? Lecturing or not?," in International Conference on Computer Systems and Technologies CompSysTech'06, Veliko Tarnovo, Bulgaria, 2006.

[11] A. Ali and D. Smith, "Teaching an Introductory Programming Language," Journal of Information Technology Education: Innovations in Practice, vol. 13, pp. 57-67, 2014.

[12] W. P. Dann, S. Cooper and R. Pausch, Learning to Program with Alice, W. P. Dann, S. Cooper and R. Pausch, Eds., New Jersy, USA: Prentice Hall, 2006.

[13] R. B, "Making service learning accessible to computer scientists," in SIGCSE 07, Covington, 2007.

[14] M. P. Uysal, "Improving First Computer Programming Experiences: The Case of Adapting a Web-Supported and Well- Structured problem-Solving Method to a Traditional Course," Contemporary Educational Technology, vol. 5, no. 3, pp. 198-217, 2014.

[15] B. Susan, R. Reilly and D. Traynor, "Examining the role of self-regulated learning on introductory programming performance," in Proceedings of the first international workshop on Computing education research, Seattle, Washington, USA, 2005.

[16] M. Havenga, B. Breed, E. Mentz, D. Govender, I. Govender, F. Dignum and V. Dignum, "Metacognitive and problem-solving skills to promote self-directed learning in computer programming: teachers' 
experiences," SA-eDUC JOURNAL, vol. 10, no. 2, pp. 114, 2013.

[17] S. M. M and A. A. R., "Relationship of the creativity and metacognitive skills of computer students with their programming courses' grades," Scientific Journal of Education Strategies in Medical Sciences, vol. 4, no. 3, pp. 121-127, 2011.

[18] M. Muller, "A Preliminary Study on the Impact of a Pair Design Phase on Pair Programming and Solo Programming," Information and Software Technology, vol. 48, no. 5, pp. 335-344, 2006.

[19] N. Salleh, E. Mendes and J. C. Grundy, "Empirical Studies of Pair Programming for CS/SE Teaching in Higher Education: A Systematic Literature Review," IEEE Transactions on Software Engineering, vol. 37, no. 4, pp. 509-525, 2011.

[20] A. Tiwari, P. Lai, M. So and K. Yuen, "A comparison of the effects of problem-based learning and lecturing on the development of students' critical thinking," Medical Education, vol. 40, no. 6, pp. 547-554, 2006.

[21] L. Lee, "Using Web-based Instruction to Promote Active Learning: Learners' Perspectives," CALICO Journal, vol. 23, no. 1, pp. 139-156, 2005.

[22] B. Isong, "A Methodology for Teaching Computer Programming: first year students' perspective," International Journal of Modern Education and Computer Science, vol. 9, pp. 15-21, 2014.

[23] G. Bellaby, C. McDonald and A. Patterson, "WHY LECTURE?," in Proceedings of the 4thn annual Conference of the LTSN, NUI Galway, 2003.

[24] M. Konecki, "IMPROVING STUDENTS' FOCUS IN INTRODUCTORY PROGRAMMING COURSES," in DAAAM INTERNATIONAL SCIENTIFIC BOOK 2015, B. Katalinic, Ed., Vienna, Austria, DAAAM International, 2015, pp. 165-172.

[25] J. M. G. C'ardenas and I. D. Sanders, "Introductory Programming Course: From Classics to Formal Methods," in WCECS, San Francisco, 2009.

[26] W. Lowe, "Is the Sun Setting on Lecture-based Education?," International Journal of Therapeutic Massage \& Bodywork: Research, Education, \& Practice, vol. 4, no. 4, pp. 7-9, 2011.

[27] M. L. Costa, L. V. Rensburg and N. Rushton, "Does teaching style matter? A randomised trial of group discussion versus lectures in orthopaedic undergraduate teaching," Medical Education, vol. 41, no. 2, pp. 214-217, 2007.

[28] D. A. Bligh, Evidence what lectures achieve, San Francisco: Jossey-Bass, 2000, pp. 1-20.

[29] I. Huet, O. R. Pacheco, J. Tavares and G. Weir, "New Challenges in Teaching Introductory Programming courses: A Case Study," in ASEE/IEEE Frontiers in Education Conference, Savannah, GA, 2004.

[30] D. M. Horton, S. D. Wiederman and D. A. Saint, "Assessment outcome is weakly correlated with lecture attendance: influence of learning style and use of alternative materials," Advances in Physiology Education, vol. 36, no. 2, pp. 108-115, 2012.

[31] F. V. Gaal and A. D. Ridder, "The Impact of assessment tasks on subsequent examination performance," Active Learning in Higher Education, vol. 14, no. 3, pp. 213-225, 2013.

[32] E. Kaila, T. Rajala and S. Mikko-Jussi Laakso, "Automatic Assessment of Program Visualization Exercises," in 8th koli Calling International Conference on Computing Education Research, Joensuu, Finland, 2008.
[33] B. Kennelly and J. C. \&. D. Flannery, "Online Assignments in Economics: A Test of Their Effectiveness," The Journal of Economic Education, vol. 42, no. 2, pp. 136-146, 2011.

[34] S. E. Gump, "The Cost of Cutting Class: Attendance As A Predictor of Success," College Teaching, vol. 53, no. 1, pp. 21-26, 2005.

[35] D. R. Marburger, "Does Mandatory Attendance improve Student Performance?," The Journal of Economic Education, vol. 37, no. 2, pp. 148-155, 2006.

[36] T. Koulouri, S. Lauria and R. D. Macredie, "Teaching Introductory Programming: A Quantitative Evaluation of Different Approaches," ACM Transactions on Computing Education (TOCE), vol. 14, no. 4, pp. 26.1-26.27, 2014.

[37] T. C. Reeves, "How do you know they are learning?: the importance of alignment in higher education," International Journal of Learning Technology, vol. 2, no. 4, pp. 294-309, 2006.

[38] J. Richard O. Mines, "The Impact of Testing Frequency and Final Exams on Student Performance," in ASEE Southeast Section Conference : American Society for Engineering Education, 2014, Macon, GA, 2014.

[39] V. Mlambo, "An analysis of some factors affecting student academic performance in an introductory biochemistry course at the University of West Indies," Caribbean Teaching Scholar, vol. 1, no. 2, pp. 79-92, 2011.

[40] J. Biggs, "What the student does: Teaching for enhanced learning in the '90s," Journal of the Higher Education Research and Development Society of Australasia, vol. 18, no. 1, pp. 57-75, 1998.

[41] I. Alastair, An Investigation into the Impact of Formative Feedback on the Student Learning Experience, Durham University, 2010.

[42] O. Eren and D. J. Henderson, "The impact of homework on student achievement," The Econometrics Journal, vol. 11, no. 2, pp. 326-348, 2008.

[43] M. T. Carrillo-de-la-Pena, E. Bailles, X. Caseras, A. Martinez, G. Ortet and J. Perez, "Formative assessment and academic achievement in pre-graduate students of health sciences," Adv in Healh Science Education, vol. 14, no. 1, pp. 61-67, 2009.

[44] B. C. Wilson and S. Shrock, "Contributing to Success in an Introductory Computer Science Course: A Study of Twleve Factors," ACM SIGCSE Bulletin, vol. 33, no. 1, pp. 184-188, 2001.

[45] R. Lister and J. Leaney, "Introductory Programming, criterion-referencing and bloom," ACM SIGCE BULLETIN, vol. 35, no. 1, pp. 143-147, 2003.

[46] S. Shuhidan, M. Hamilton and D. D'Souza, "Instructor perspectives of multiple-choice questions in summative assessment for novice programmers," Computer Science Education, vol. 20, no. 3, pp. 229-259, 2010.

[47] V. J. Shute, "Focus on Formative Feedback," Educational Testing Service, 2008.

[48] A. T. Corbett and J. R. Anderson, "Locus of feedback control in computer-based tutoring: Impact on learning rate, achievement and attitudes," in In Proceedings of the SIGCHI Conference on Human Factors in Computing Systems, New York, 2001.

[49] C. Redecker, "The Use of ICT for the Assessemnt of Key Competences," European Commission, Joint Research Centre, Institute for Prospective Technological Studies, Luxembourg, 2013.

[50] J. Holvitie, R. Haavisto, E. Kaila, M.-J. L. Teemu Rajala and T. Salakoski, "Electronic exams with automatically assessed exercises," in ICEE 2012 - International 
Conference on Engineering Education, Turku, Finland, 2012.

[51] I. Miliszewska and G. Tan, "Information and Beyond Issues in Informing Science \& Information Technology," in Befriending Computer Programming: A proposed Approach to Teaching Introductory Programming, Santa Rosa, Informing Science Press, 2007, pp. 277-289.

[52] C. A. Higgins, G. Gray, P. Symeonidis and A. Tsintsifas, "Automated assessment and experiences of teaching programming," Journal on Educational Resources in Computing, vol. 5, no. 3, pp. 1-21, 2005.

[53] R. Alexandre, P. Queiros and J. P. Leal, "PETCHA: a programming exercises teaching assistant," in ITiCSE'1217th ACM annual conference on Innovation and technology in computer science education, Haifa, Israel, 2012.

[54] M. Sherman, S. Bassil, D. Lipman, N. Tuck and F. Martin, "Impact of auto-grading on an introductory computing course," Journal of Computing Sciences in Colleges, vol. 28, no. 6, pp. 69-75, 2013.

[55] G. Mallik, "Lecture and Tutorial Attendance and Student Performance in the First year economics course: A quantile regression approach," American Economic Association Annual Meeting, Denver, United States, 2011.

[56] J. Chen and T.-F. Lin, "Class Attendance and Exam Performance: A Randomized Experiment," he Journal of Economic Education, vol. 39, no. 3, pp. 213-227, 2008.

[57] T.-F. lin and J. Chen, "Cumulative class attendance and exam performance," Applied Economics Letters, vol. 13, no. 14, pp. 937-942, 2006.

[58] M. L. V. Blerkom, "Class Attendance in Undergraduate Courses," The Journal of Psychology, vol. 126, no. 5, pp. 487-494, 1992.

[59] D. R. Marburger, "Absenteeism and Undergraduate Exam Performance," The Journal of Economic Education, vol. 32, no. 2, pp. 99-109, 2001.

[60] M. Credé, S. G. Roch and U. M. Kieszczynka, "Class Attendance in College: A Meta-Analytic Review of the Relationship of Class Attendance With Grades and Student Characteristics," Review of Educational Research, vol. 80, no. 2, pp. 272-295, 2010.

[61] P. Purcell, "Engineering Student Attendance at Lectures: Effect on Examination Performance," in International Conference on Engineering Education - ICEE 2007 , Coimbra, Portugal, 2007.

[62] V. Nehra and A. Tyagi, "Free Open Source Software in Electronics Engineering Education: A Survey," International Journal of Modern Education and Computer Science, vol. 5, pp. 15-25, 2014.

[63] T. Traphagan, J. V. Kucsera and K. Kishi, "Impact of class lecture webcasting on attendance and learning," Educational Technology Research and Development, vol. 58, no. 1, pp. 19-37, 2009.

[64] K. HU, K. AM, M. IU, M. A, A. S, K. MH, S. M and S. $\mathrm{SH}$, "Impact of class attendance upon examination results of students in basic medical sciences," Journal of Ayub Medical College, Abbottabad, vol. 15, no. 2, pp. 56-58, 2002.

[65] "https://moodle.utu.fi/," [Online]. [Accessed 2501 2016].

[66] Z. F. Muhsen, A. Maaita, A. Odah and A. Nsour, "Moodle and e-learning Tools," International Journal of Modern Education and Computer Science, vol. 6, pp. 1-8, 2013.

[67] "ViLLE," University of Turku, [Online]. Available: http://villeteam.fi/index.php/en/. [Accessed 2010 2015].

[68] A. Ghasemi and S. Zahediasl, "Normalaity Tests for Statistical Analysis: A guide for Non-Statisticians,"
International Journal of Endocrinology Metabolism, vol. 10, no. 2, pp. 486-489, 2012.

[69] J. Jauke and T. Kossowski, "Comparison of values of Pearon's and Spearman's Correlation Coefficients on the sames sets of Data," Quaestiones geographicae, vol. 30, no. 2, pp. 87-93, 2011.

[70] J. Higgins, "Introduction to Multiple Regression," in The Radical Statistician, 2005, pp. 1-26.

[71] H. Cooper, J. C. Robinson and E. A. Patall, "Does Homework Improve Academic Achievement? A Synthesis of Research 1987-2003," Review of Educational Research, vol. 76, no. 1, pp. 1-62, 2006.

[72] E. Cohn and E. Johnson, "Class attendance and performance in Principles of Economics," Education Economics, vol. 14, no. 2, pp. 211-233, 2006.

\section{Authors' Profiles}

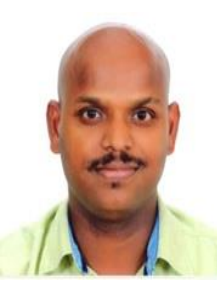

Mr. Ashok Kumar Veerasamy is a researcher (doctoral student) in the ViLLE Team Research Project at University of Turku, Finland. He received his postgraduate degree in Computer Applications and advanced postgraduate research degree in Computer Science, at Madurai Kamaraj University, India. He did his degree of Graduate Certificate in Tertiary Teaching and Learning at RMIT University, Australia. His research and publication interests lie in the area of computer science \& IT education, educational technologies (ViLLE) in teaching and learning, and computational aspects of learning analytics.

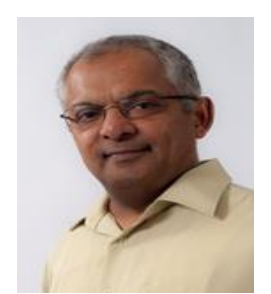

Dr. Daryl D'Souza has been an academic member of the School of Computer Science \& IT, RMIT University, Melbourne, since 1983, and has contributed substantially to all facets of university life, including teaching, research, leadership and community engagement. He holds a PhD (2005) in Computer Science, in information retrieval. He has extensive teaching experience at both undergraduate and postgraduate coursework levels and is presently largely involved in first year teaching of programming. This latter activity is an important part of his reflective teaching practice and scholarly activity in the area of computing education research and since has added computing education research to his research interests, which include learning analytics. He has published in computing education research since 2011, has chaired national computing education conferences, and has been an investigator in several research grants to investigate curriculum and pedagogy issues around novice programming.

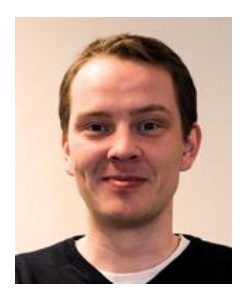

Mr. Rolf Lindén (M.Sc. in mathematics and in computer science), is working on his $\mathrm{PhD}$ about automated student profiling and counseling. He has 13 publications in peerreviewed journals and conference proceedings, and in 2013 he participated in setting up an education-related start-up firm. His research interests include data analysis, mathematics and machine learning. Lindén has been working on ViLLE project since the spring of 2012. 


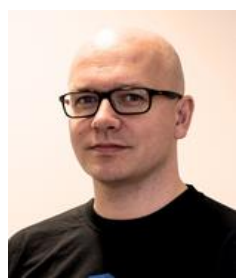

Mr. Erkki Kaila is currently finishing his $\mathrm{PhD}$ in the Department of Information Technology, University of Turku about utilizing educational technology effectively. His research interests include program visualization, learning environments, automatic assessment, programming educations and course design utilizing new technologies.

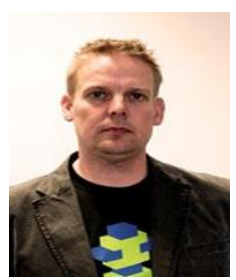

Dr. Mikko-Jussi Laakso is an Adjunct Professor at Department of Information Technology, University of Turku, Finland. Mikko did his PhD (2010) in Information Technology (Promoting Programming Learning) at University of Turku, Finland. $\mathrm{He}$ is also a research head of ViLLE team research project. He has presented papers in the area of learning analytics and ViLLE learning environment at conferences both home and abroad, published articles and papers in various journals since 2007. His research and publication interests include program and algorithm visualization, learning environments, computer aided and automatic assessment in computer science education.

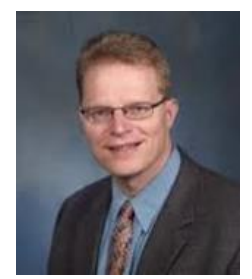

Dr. Tapio Salakoski, $\mathrm{PhD}$, is a professor of Computer Science at University of Turku. He is the Dean of Science and Technology Education at the university, and the Head of the Department of Information Technology. He has more than 200 scientific publications in international journals and conference proceedings, and has supervised more than $10 \mathrm{PhDs}$ and numerous MScs. He serves in scientific editorial boards and has organized and chaired international conferences. He is heading a large research group studying machine intelligence methods and interdisciplinary applications, especially information retrieval and natural language processing in the biomedical and health care domain as well as technologies related to human learning, language, and speech.

How to cite this paper: Ashok Kumar Veerasamy, Daryl D'Souza, Rolf Lindén, Erkki Kaila, Mikko-Jussi Laakso, Tapio Salakoski ,"The Impact of Lecture Attendance on Exams for Novice Programming Students", International Journal of Modern Education and Computer Science(IJMECS), Vol.8, No.5, pp.1-11, 2016.DOI: 10.5815/ijmecs.2016.05.01 